\title{
Surfactants Influence Foliar Absorption of Gibberellic Acid by Sour Cherry Leaves
}

\author{
Moritz Knoche and Martin J. Bukovac \\ Department of Horticulture, Michigan State University, East Lansing MI 48824-1325
}

Additional index words. contact angle, deposit formation, $\mathrm{GA}_{3}$, Prunus cerasus, surface tension

\begin{abstract}
The effects of selected surfactants and surfactant blends, frequently used in spray application, on deposit formation and foliar absorption of $\mathbf{G A}_{3}$ by sour cherry (Prunus cerasus $\mathbf{L}$. CV. Montmorency) have been investigated. Globular deposits were observed on droplet drying from solutions without surfactants or when the surfactants Activator 90, Tween 20, or Silwet L-77 were present, while annular-shaped deposits were observed with Regulaid, Ortho $\mathrm{X}-77$, and Triton AG-98. Absorption of $\mathrm{GA}_{3}$ without surfactant was 5- and 17 -fold higher by the abaxial $(8.5 \%$ and $20.2 \%$ of applied in 1988 and 1989) than adaxial surface (1.6\% and $1.2 \%$ of applied in 1988 and 1989). Over 24 hours, Ortho X-77 and Activator $90(45.7 \%$ vs. $33.7 \%$ in $1988,42.5 \%$ vs. $41.7 \%$ in 1989) were most effective in enhancing $\mathrm{GA}_{3}$ penetration through the abaxial surface, followed by Triton AG-98 (38.6\% in 1988), Tween 20 (28.6\% in 1989), and Regulaid $\left(23.6 \%\right.$ in $1988,16.8 \%$ in 1989). Silwet L-77 significantly reduced GA uptake $^{(10.7 \%}$ in 1989) compared with the nonsurfactant control $\left(18.2 \%\right.$ in 1989). $\mathbf{G A}_{3}$ uptake increased at a decreasing rate during a 96-hour absorption period when $\mathrm{GA}_{3}$ was applied alone or with Ortho X-77. However, uptake increased linearly

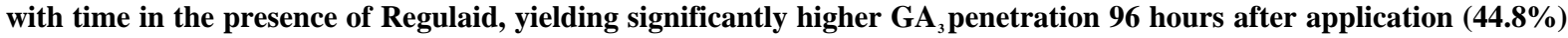
compared with GA, alone $(11.3 \%)$ or $\mathbf{G A}_{3}$ with Ortho X-77 $(27.7 \%)$. $\mathrm{GA}_{3}$ penetration was independent of Tween 20 concentration in the range from $0.0313 \%$ to $0.25 \%$ but increased with increasing Ortho $X-77$ concentration $(0.0313 \$ \%$ to $\mathbf{0 . 2 5 \%}$ ) over a $\mathbf{2 4}$-hour absorption period. Chemical names used: alkylpolyoxyethylene ether, free fatty acids, isopropanol (Activator 90); alkylarylpolyoxyethyleneglycols, free fatty acids and isopropanol (Ortho X-77); polyoxyethylenepolypropoxypropanol, alkyl 2-ethoxy-ethanol (Regulaid); polyalkyleneoxide modified polydimethylsiloxane copolymers (Silwet L-77); alkylarylpolyethylene glycol (Triton AG-98); polyoxyethylene (20) sorbitan monolaurate (Tween 20); gibberellic acid $\left(\mathbf{G A}_{3}\right)$.
\end{abstract}

Surfactants are frequently used in pesticide formulations to increase efficacy of foliar-applied agrochernicals. Generally, the increase in efficacy is, related to an increase in the amount of a.i. reaching the site of action. This difference may be related to an increase in the dose retained by the leaf and/or to an increase in the amount of the a.i. that penetrated the tissue. Whereas spray retention (i.e., dose) is related to the physiochemical characteristics of the spray solution and wetting characteristics of the leaf surface, the mode of action of surfactants on absorption of the a.i. is not well understood. Holloway and Stock (1990) concluded that promotion of a.i. uptake by surfactants is a complex interactive process among the a.i., surfactant, and plant. Surfactant enhancement of a.i. uptake currently cannot be predicted and has to be determined experimentally. This is particularly true for plant growth regulators, where an acceptable response is usually achieved over a narrow concentration range. In theory, for consistent response, the amount of a.i. reaching the site of action should remain the same regardless of whether surfactants are added to the spray solution. Consequently, the dose applied must be reduced if surfactants enhance foliar penetration.

GAS applied to cherry-yellows-infected sour cherry trees inhibits flower initiation and promotes spur formation (Bukovac et al., 1986a; Parker et al., 1969), and annual foliar applications are recommended for increasing fruiting potential and cropping efficiency (Bukovac et al., 1986a). Recent data on foliar uptake of $\mathrm{GA}_{3}$ in Citrus suggest marked differences in efficacy among surfactants (Coggins et al., 1989; Greenberg et al., 1984, 1987).

Received for publication 30 Apr. 1991. Accepted for publication 15 Aug. 1991 We thank Warren E. Shafer, Abbott Laboratories, for the gift of the radiolabeled $\mathrm{GA}_{3}$ and Robert J. Cibulski for financial support. This study was supported in part by the Michigan Agriculture Experiment Station and by a grant (SCA no. 58-5114-7-1002) from the Agricultural Research Service, U.S. Dept. of Agriculture. The cost of publishing this paper was defrayed in part by the payment of page charges. Under postal regulation, this paper therefore must be hereby marked advertisement solely to indicate this fact.
However, we know of no published data on effects of surfactants on uptake of $\mathrm{GA}_{3}$ by sour cherry leaves.

The purpose of this study was to investigate the effects of surfactants that are commercially available and frequently used by growers on the uptake of $\mathrm{GA}_{3}$ by sour cherry leaves. Further, physical properties of the spray solutions and their interaction with the sour cherry leaf surface were determined and are discussed in relation to $\mathrm{GA}_{3}$ performance.

\section{Materials and Methods}

Plant material. Leaves were obtained from 'Montmorency' sour cherry trees grown without pesticide application at the Horticulture Research Center, East Lansing, Mich. Leaves were detached as they attained full expansion (between 1 June and 30 July 1988 and 1989) from the third to the fifth node (counted from the apex) of current season's shoot growth. Environmental conditions were considerably different during the two seasons (Fig. 1). Above average temperatures and extremely low rainfall occurred in Spring and Summer 1988, while moderate temperatures with higher precipitation occurred in 1989. All experiments were carried out using leaf disks as a model system except for the time-course study. Disks (21 mm diameter) were punched from the lamella on both sides of the midrib and floated on distilled water in petri dishes kept at $25 \mathrm{C}$ in a water bath. Photosynthetically active radiation (PAR) was provided at 230 $\mu \mathrm{mol} \cdot \mathrm{m}^{-2} \cdot \mathrm{s}^{-1}$ during a $16-\mathrm{h}$ photoperiod. For the time-course study, detached leaves were placed in glass vials with petioles immersed in deionized water. Vials with leaves were transferred to a growth chamber providing the following conditions: 25/ 20C, day/night PAR, $150 \mu \mathrm{mol} \cdot \mathrm{m}^{-2} \cdot \mathrm{s}^{-1}$; photoperiod, $16 \mathrm{~h}$.

Chemicals. Spray solutions were prepared at a concentration of $0.5 \mathrm{~mm} \mathrm{GA}_{3}$ using $\left[1,7,12,18{ }^{14} \mathrm{C}\right]$-labeled $\mathrm{GA}_{3}(251$ $\mathrm{MBq} \cdot \mathrm{mmol}^{-1}$ specific activity, 99\% radiochemical purity, Amersham, Arlington Heights, 111.). Solutions were buffered with $20 \mathrm{mM}$ citric acid titrated to $\mathrm{pH} 3.0$ with $\mathrm{NaOH}$. Surfactants were commercial preparations and use rates were based 


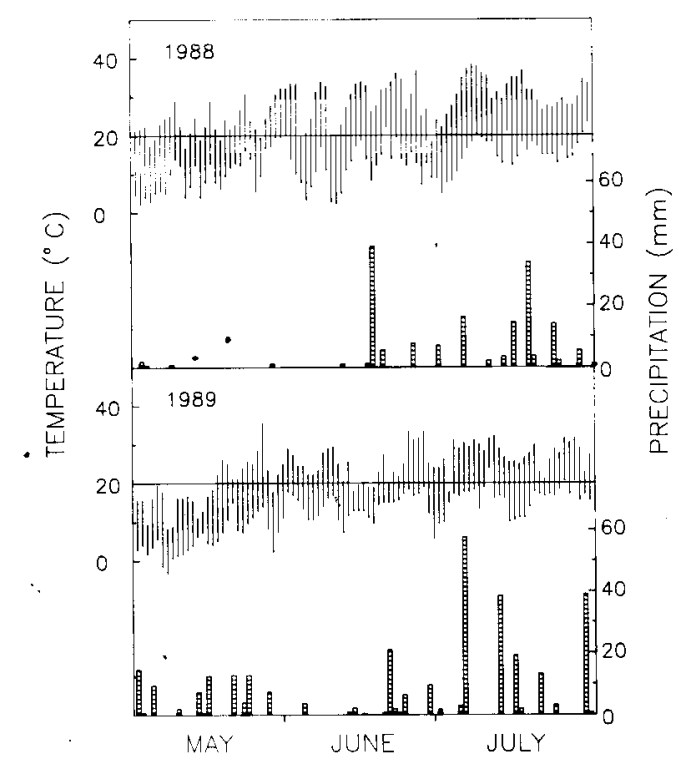

Fig. 1. Daily minimum and maximum temperature and precipitation records during development of sour cherry leaves (1 May -31 July 1988 and 1989). Data were obtained at the Horticulture Research Center, East Lansing, Mich.

on manufacturer's recommendations: Activator 90 (O. 125\%, Loveland Ind., Greeley, Colo.), Ortho X-77 (0.0625\%, Chevron Chemical, San Francisco), Regulaid (0.25\%, Kalo Laboratories, Kansas City, Me.), Silwet L-77 (0.1\%, Union Carbide, Tarrytown, N.Y.), Triton AG-98 (0.0625\%, Rohm and Haas, Philadelphia), and Tween 20 (0.125\%, ICI Americas, Wilmington, Del.). Unless otherwise stated, spray solutions were prepared $12 \mathrm{~h}$ before use.

Treatment and sampling. Spray solutions were applied as fifteen $0.24-\mu l$ droplets with a microsyringe fitted with a tefloncoated needle and an automatic dispenser (Hamilton, Reno, Nev.). Most of the data presented were limited to the abaxial surface, since previous studies indicated very little $\mathrm{GA}_{3}(<3.5 \%$ of applied) penetration through the adaxial surface (Knoche et al., 1989). Treatments were applied within $2 \mathrm{~h}$ of leaf collection. Except for the time-course and concentration response studies, uptake was determined $24 \mathrm{~h}$ after treatment.

Droplet residues were removed by rinsing the treated area (leaf disks with $5 \mathrm{ml}$ and leaves with $10 \mathrm{ml}$ ) with acetone : water $(3: 2 \mathrm{v} / \mathrm{v})$. A 1-ml aliquot was used for determination of radioactivity. Epicuticular wax and associated radiolabeled GA, were removed by cellulose acetate stripping (Silcox and Holloway, 1986). The cellulose acetate strippings were dissolved in a dioxane-based scintillation cocktail. The remainder of the leaf tissue was oxidized in a biological oxidizer (Model OX400, Harvey Inc, Hillsdale, N.J.) and the evolved ${ }^{14} \mathrm{CO}_{2}$ trapped in scintillation cocktail containing Carbo-Sorb $(2: 1 \mathrm{v} / \mathrm{v})$. Radioactivity was determined by liquid scintillation spectrometry. Uptake was calculated as percent of total applied from the sum of the radioactivity in the cellulose acetate stripping and the oxidized leaf tissue. Average recovery of radioactivity was $98.4 \%$.

$\mathrm{GA}_{3}$ absorption experiments. The effect of selected surfactants on $\mathrm{GA}_{3}$ absorption was determined using sour cherry leaf disks. Disks were radioassayed $24 \mathrm{~h}$ after application. Experiments were performed twice in 1988 and three times in 1989 with 10 replications per treatment. Data presented are means for all experiments.

The time-course study was conducted using detached leaves.
Sampling times were 1, 6, 12,24, 48, and $96 \mathrm{~h}$ after treatment. Ten single-leaf replicates were used for each treatment.

In the concentration-response study, spray solutions of Ortho X-77 and Tween 20 were prepared at concentrations of $0.0313 \%$, $0.0625 \%, 0.125 \%$, and $0.25 \%$. Leaf disks were harvested 24 and $96 \mathrm{~h}$ after application. Ten replications (disks) were used for the 24-h and five for the 96-h sampling time.

Measurements of spray solution properties. For measurement of surface tension, $10 \mathrm{ml}$ of surfactant solution was transferred into glass petri dishes and equilibrated for $1 \mathrm{~h}$. Surface tension was determined using a Fisher Model 20 surface tensiometer (Fisher Scientific, Pittsburgh). Each determination was replicated five times.

Contact angles formed by $1-\mu$ d droplets of the treatment solution with the abaxial leaf surface were determined during the 1988 and 1989 growing seasons. Base width and height of droplets were measured and contact angles calculated according to Mack's equation (Mack, 1936). A minimum of five determinations was made on each of 10 leaves.

The effect of surfactants on drying time of the spray droplets was determined in 1989. Ten $0.24-\mu$ droplets were applied to the abaxial surface of each leaf disk. Disks were held in petri dishes in a water bath at 25C. Drying time of the first and the last droplet for each disk was determined visually. A mean drying time was calculated, each disk representing one observation. All determinations were replicated 10 times.

Deposits of dried droplets of spray solutions containing $\mathrm{GA}_{3}$, citrate buffer, and surfactant were examined by scanning electron microscopy (SEM). Excised leaf tissue was mounted on aluminum stubs with carbon adhesive, and discrete droplets $(0.24$ $\mu \mathrm{l})$ were applied to the abaxial leaf surface using a microsyringe. Specimens were then placed in a chamber maintained at $25 \mathrm{C}$ and $45 \%$ relative humidity. After droplet drying $(\approx 15$ rein), the samples were used for SEM (ISI 40, International Scientific, Pleasanton, Calif.) without further preparation.

Statistics. A completely randomized design was used for the $\mathrm{GA}_{3}$ absorption experiments. Data were subjected to analysis of variance where appropriate. Since not all surfactants were tested in both growing seasons, experiments were analyzed with surfactants being the only factor. Means were compared using Duncan's multiple range test at $P=0.05$. Standard errors are included in all graphs except where smaller than data symbols.

\section{Results}

Surfactants significantly decreased surface tension, contact angle, and drying time of spray droplets, Triton AG-98 and Ortho X-77 being more effective than Regulaid, Tween 20, Activator 90, and Silwet L-77 (Table 1). Contact angles were consistently lower in 1989 than in 1988. Drying time was significantly reduced by all surfactants except Silwet L-77.

Surfactants had a marked effect on deposit formation from spray droplets (Fig. 2). Globular deposits were observed with solutions containing no surfactant (Fig. 2A), Activator 90 (Fig. 2B), Tween 20 (Fig. 2C), or Silwet L-77 (Fig. 2D), while solutions containing Regulaid (Fig. 2E), Ortho X-77 (Fig. 2F), and Triton AG-98 (Fig. 2G) formed annular deposits with much larger interface areas. Deposits were often associated with veins.

Uptake of $\mathrm{GA}_{3}$ by sour cherry leaves was markedly affected by growing season and leaf surface (Table 2). During the warm, dry growing season of 1988 (Fig. 1) average uptake, calculated from all experiments conducted under comparable conditions . (i.e., $0.5 \mathrm{mM} \mathrm{GA}_{3}, \mathrm{pH} 3.0,25 \mathrm{C}, 230 \mu \mathrm{mol} \cdot \mathrm{m}^{-2} \cdot \mathrm{s}^{-1} \mathrm{PAR}$ ), was about five times higher through the abaxial than the adaxial 
Table 1. Effect of selected surfactants at manufacturers' recommended concentrations on surface tension of the spray solution, contact angle formed between $1-\mu \mathrm{l}$ droplets and the abaxial surface of sour cherry leaves and droplet drying time.

\begin{tabular}{|c|c|c|c|c|c|}
\hline \multirow[b]{2}{*}{ Surfactant } & \multirow{2}{*}{$\begin{array}{c}\text { Concn } \\
(\%)\end{array}$} & \multirow{2}{*}{$\begin{array}{c}\text { Surface } \\
\text { tension } \\
\left(\mathrm{mN} \cdot \mathrm{m}^{-1}\right)\end{array}$} & \multicolumn{2}{|c|}{$\begin{array}{c}\text { Contact angle } \\
\left({ }^{\circ}\right)\end{array}$} & \multirow{2}{*}{$\begin{array}{c}\text { Drying } \\
\text { time } \\
\text { (min) }\end{array}$} \\
\hline & & & 1988 & 1989 & \\
\hline Control & -- & $70.8 a^{z}$ & $81.5 \mathrm{a}$ & $55.8 \mathrm{a}$ & $13.6 \mathrm{a}$ \\
\hline Triton AG 98 & 0.0625 & $27.1 \mathrm{~g}$ & $32.7 \mathrm{~d}$ &.$- y$ & $\ldots y$ \\
\hline Ortho X-77 & 0.0625 & $27.8 \mathrm{f}$ & $29.3 d$ & $27.0 \mathrm{e}$ & $9.7 \mathrm{~b}$ \\
\hline Activator 90 & 0.125 & $32.3 \mathrm{e}$ & $43.7 \mathrm{~b}$ & $39.2 \mathrm{c}$ & $10.2 \mathrm{~b}$ \\
\hline Tween 20 & 0.125 & $33.2 \mathrm{~d}$ & $\ldots x$ & $34.0 \mathrm{~d}$ & $10.9 \mathrm{~b}$ \\
\hline Regulaid & 0.25 & $35.4 \mathrm{c}$ & $38.7 \mathrm{c}$ & $31.0 \mathrm{~d}$ & $9.1 \mathrm{~b}$ \\
\hline Silwet L-77 & 0.1 & $50.9 \mathrm{~b}$ & $---x$ & $49.4 \mathrm{~b}$ & $13.6 \mathrm{a}$ \\
\hline
\end{tabular}

${ }^{2}$ Mean separation within columns by Duncan's multiple range test, $P=0.05$

Not determined in 1989.

${ }^{x}$ Not determined in 1988.

surface. In 1989, uptake by the abaxial surface of leaves, which developed during cool and wet growing conditions (Fig. 1), was 17 times greater than adaxial uptake (Table 2). This difference was mainly the result of increased absorption by the abaxial surface (from $8.5 \%$ in 1988 to $20.2 \%$ in 1989), whereas penetration through the adaxial surfaces remained nearly constant (Table 2). Variation in uptake was less pronounced in 1989 than 1988. When uptake was calculated on a droplet/leaf interface area basis, differences between leaf surfaces within years remained nearly the same (6-fold in 1988 and 15-fold in 1989). However, differences in abaxial $\mathrm{GA}_{3}$ uptake between the two growing seasons decreased from 2.4-fold greater uptake (percent of applied basis) in 1989 to 1.6-fold greater uptake in 1989, when uptake was calculated on an interface area basis.

$\mathrm{GA}_{3}$ absorption varied with surfactant (Table 3). In 1988, $\mathrm{GA}_{3}$ penetration in the presence of Ortho $\mathrm{X}-77$ was $45.7 \%$ in comparison with $8.7 \%$ for the control, followed by Triton AG98, Activator 90, and Regulaid. In the following year (1989),
Ortho X-77 and Activator 90 were most effective in enhancing $\mathrm{GA}_{3}$ uptake, followed by Tween 20 . No significant change in absorption was observed when Regulaid was added. Silwet L77 depressed $\mathrm{GA}_{3}$ uptake. The effect of growing season was greatest in the absence of surfactants $(8.7 \%$ in 1988 vs. $18.2 \%$ in 1989); the average uptake in presence of the surfactants tested in both years was similar (34.3\% in 1988 vs. $33.7 \%$ in 1989).

Enhancement of $\mathrm{GA}_{3}$ absorption by Regulaid and Ortho X77 differed markedly in level of uptake and kinetics (Fig. 3). Rates of $\mathrm{GA}_{3}$ absorption decreased over time when $\mathrm{GA}_{3}$ only (control) and $\mathrm{GA}_{3}$ combined with Ortho X-77 were applied, but Ortho X-77 significantly increased uptake. In the presence of Regulaid, $\mathrm{GA}_{3}$ absorption increased linearly over the entire experimental period [(uptake in \%) $=0.32+0.45$ (time in $\mathrm{hr}$ ), $\left.r^{2}=0.99^{* *}\right]$. After $96 \mathrm{~h}$, uptake was significantly higher than for the control or for Ortho X-77 (Fig. 3).

In the concentration-response study (Fig. 4), Tween 20 and Ortho X-77 enhanced $\mathrm{GA}_{3}$ uptake at all concentrations. Differences in $\mathrm{GA}_{3}$ uptake between the various Tween 20 concentrations $(0.0313 \%$ to $0.25 \%)$ were not significant, while Ortho X77 was more effective at the highest than at the lowest concentrations $(0.0313 \%$ vs. $0.25 \%)$. Differences in penetration between the 24- and 96-h sampling time were greater for $\mathrm{GA}_{3}$ applied with Tween 20 than with Ortho X-77.

\section{Discussion}

Inconsistent performance of foliar-applied agrochemicals can be a serious limitation to field use. Variation in efficacy of systemic pesticides, growth regulators, and foliar fertilizer may be partly related to variation in foliar absorption of the active ingredient (Bukovac et al., 1986b). Foliar absorption depends on physical and chemical properties of the spray solution, morphological and physiological characteristics of the plant, and environmental conditions during spray application. In our study, environmental conditions during and after spray application remained constant, since experiments were carried out in a controlled environment. Nevertheless, previous environmental

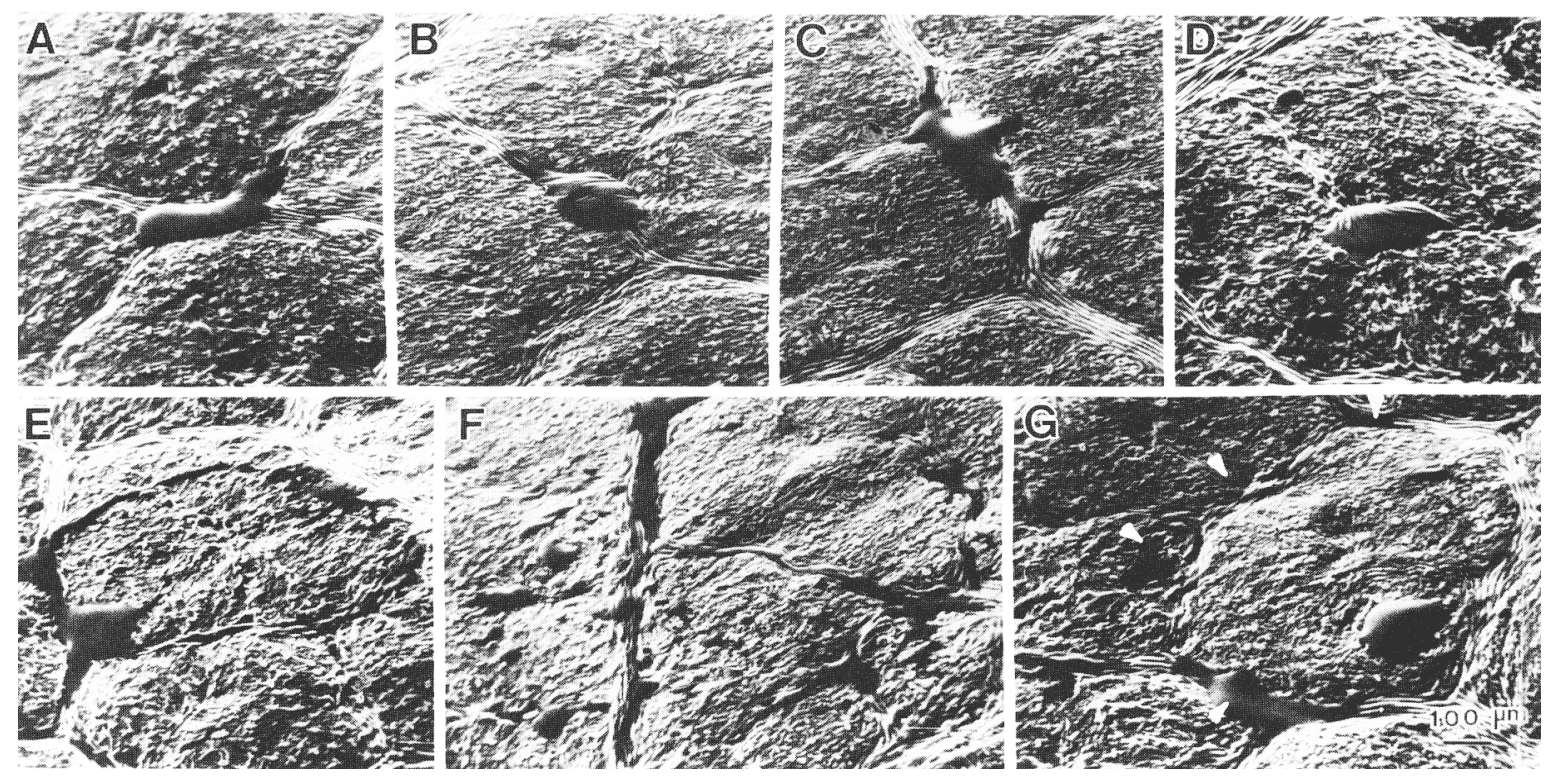

Fig. 2. Effect of selected surfactants on form of deposit on sour cherry leaves from spray droplets containing GA, and citric acid buffer. (A) Control, no surfactant. (B) Activator 90. (C) Tween 20. (D) Silwet L-77. (E) Regulaid. (F) Ortho X-77. (G) Triton AG-98 (arrows denote localized residue). 
Table 2. Means and coefficients of variation of $\mathrm{GA}_{3}$ absorption by sour cherry leaves during the 1988 and 1989 growing seasons. Data are means calculated from all control treatments (no surfactant) conducted under similar conditions $\left(0.5 \mathrm{~mm} \mathrm{GA}_{3}, \mathrm{pH} 3.0,25 \mathrm{C}, 230\right.$ $\mu \mathrm{mol} \cdot \mathrm{m}^{-2} \cdot \mathrm{s}^{-1} \mathrm{PAR}, 24-\mathrm{h}$ uptake period).

\begin{tabular}{llclll}
\hline \hline & \multicolumn{4}{c}{$\mathrm{GA}_{\mathbf{3}}$.uptake } \\
\cline { 2 - 3 } Leaf & \multicolumn{2}{c}{ \% of applied } & & \% of applied $/ \mathrm{mm}^{2}$ \\
\cline { 2 - 3 } \cline { 5 - 6 } surface & 1988 & 1989 & & 1988 & 1989 \\
\hline Adaxial & $1.6^{\mathbf{z}}(59.2)$ & $1.2^{\mathrm{y}}(41.3)$ & & 0.6 & 0.4 \\
Abaxial & $8.5^{\mathrm{x}}(41.8)$ & $20.2^{\mathrm{w}}(24.0)$ & & 3.7 & 5.8 \\
\hline
\end{tabular}

${ }^{\mathrm{z}} \mathrm{n}=80$

${ }^{\mathrm{y}} \mathrm{n}=30$.

${ }^{\mathrm{x}} \mathrm{n}=100$.

${ }^{\mathrm{w}} \mathrm{n}=40$.

Table 3. Effect of selected surfactants at manufacturers' recommended concentrations on $\mathrm{GA}_{3}$ uptake by the abaxial sour cherry leaf surface.

\begin{tabular}{|c|c|c|c|c|c|}
\hline \multirow[b]{3}{*}{ Surfactant } & \multirow{3}{*}{$\begin{array}{c}\text { Concn } \\
(\%)\end{array}$} & \multicolumn{4}{|c|}{$\mathrm{GA}_{3}$ uptake } \\
\hline & & \multicolumn{2}{|c|}{$\%$ of applied } & \multicolumn{2}{|c|}{$\%$ of control } \\
\hline & & 1988 & 1989 & 1988 & 1989 \\
\hline Control & -.- & $8.7 d^{2}$ & $18.2 \mathrm{c}$ & 100 & 100 \\
\hline Triton AG 98 & 0.0625 & $38.6 \mathrm{~b}$ &.$-- y$ & 441 & $--y^{y}$ \\
\hline Ortho X-77 & 0.0625 & $45.7 \mathrm{a}$ & $42.5 \mathrm{a}$ & 522 & 233 \\
\hline Activator 90 & 0.125 & $33.7 \mathrm{~b}$ & 41.7 a & 385 & 229 \\
\hline Tween 20 & 0.125 & $---x$ & $28.6 \mathrm{~b}$ & $--^{x}$ & 157 \\
\hline Regulaid & 0.25 & $23.6 \mathrm{c}$ & $16.8 \mathrm{c}$ & $270^{\circ}$ & 92 \\
\hline Silwet L-77 & 0.1 & $---x$ & $10.7 \mathrm{~d}$ & $---x$ & 59 \\
\hline
\end{tabular}

${ }^{z}$ Mean separation within columns by Duncan's multiple range test, $P=0.05$.

${ }^{y}$ Not determined in 1989 .

'Not determined in 1988.

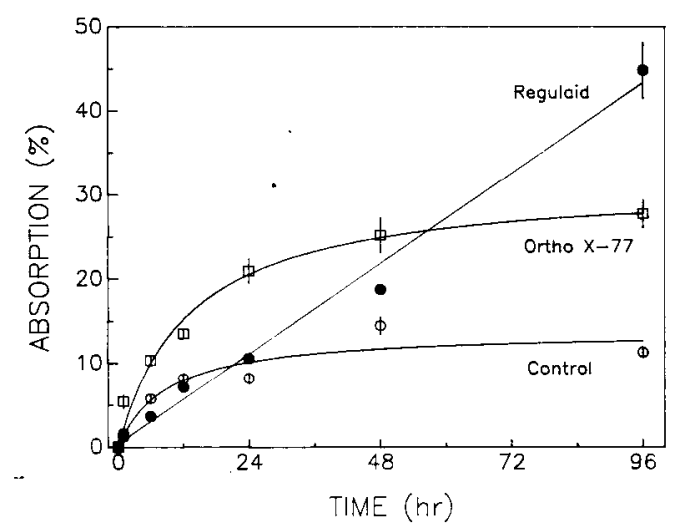

Fig. 3. Effect of Regulaid $(0.25 \%)$ and Ortho X-77 $(0.0625 \%)$ on time-course of $\mathrm{GA}_{3}$ penetration into the abaxial sour cherry leaf surface. Concentrations used were based on manufacturers' recommendation.

conditions may influence leaf characteristics. Growing conditions differed greatly between the 1988 and 1989 seasons, and this was reflected in nettability of the leaf surfaces (Table 1). The abaxial leaf surface was easier to wet in 1989 than 1988; this difference was consistent for all treatment solutions applied. Wetting characteristics of a leaf surface are related to surface fine-structure and chemistry (Fogg, 1947; Holloway, 1969). While the qualitative composition of epicuticular wax is not significantly affected by growing conditions (Baker, 1974; Taylor et al., 1981), temperature, humidity, and radiation, in particular,

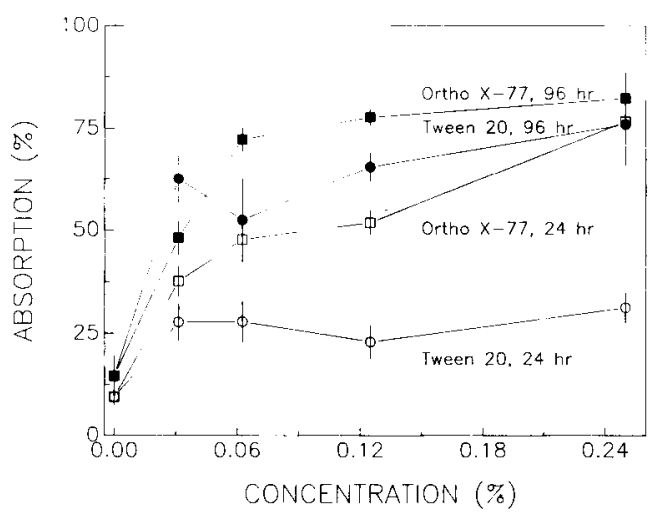

Fig. 4. Effect of Tween 20 and Ortho X-77 concentration on $\mathrm{GA}_{3}$ penetration into the abaxial sour cherry leaf surface 24 and $96 \mathrm{~h}$ after application.

can alter the quantity and modify the morphology and distribution of epicuticular wax on the surface (Baker, 1974). High radiation, low humidity, and low temperature favor wax deposition on leaf surfaces (Baker, 1974; Leece, 1978). However, plant response to temperature may vary depending on species (Leece, 1978).

The change in wetting behavior of the leaf surfaces accounted for part of the difference in uptake between the two growing seasons (Table 2). The effect of growing season was less when uptake was calculated on a droplet/leaf interface area basis representing the effective area for diffusion. If surfactant effects on $\mathrm{GA}_{3}$ uptake were compared on a unit interface area basis, differences among treatments also decreased. Regression analysis revealed that 5170 of the uptake component can be attributed to the change in droplet/leaf interface area associated with surfactant and season [(uptake in percent $)=-11.0+9.7$ (area in $\left.\mathrm{mm}^{2}\right), \mathrm{r}^{2}=0.511^{*}$ ]. Nevertheless, there still was about a 2-fold difference in enhancement of $\mathrm{GA}_{3}$ absorption between the most effective surfactant, Ortho X-77, and Regulaid or Tween 20. Additionally, uptake per unit area in 1988 remained lower than in 1989. Increased wax deposition, expected under environmental conditions of 1988, increases diffusive resistance of the cuticle (Bukovac et al., 1979; Norris and Bukovac, 1972) and most likely resulted in the lower uptake per unit area. If droplet spreading (wetting) had been the only factor, then uptake per unit interface area would have been identical in both growing seasons and for all surfactants. By expressing uptake per unit droplet/leaf interface area we assume that uptake occurs primarily during the liquid phase of the droplet. However, the time-course study suggested that absorption continued from the "dry" residue (Fig. 3). Thus, the deposit/leaf interface area needs to be considered.

Droplet spreading is and deposit formation appeared to be related to the surface tension of the spray solution. Solutions with a surface tension $>30 \mathrm{mN} \cdot \mathrm{m}^{-1}$ (i.e., control without surfactant, Activator 90, Tween 20, Silwet L-77) formed globular deposits, whereas solutions with surface tension lower than 30 $\mathrm{mN} \cdot \mathrm{m}^{-1}$ (i.e., Ortho X-77, Triton AG-98) formed annular deposits. The only exception was the deposit from solutions containing Regulaid, which, based on the surface tension of 35.4 $\mathrm{mN} \cdot \mathrm{m}^{-1}$, would have been expected to be globular instead of annular. The reason for this deviation is not known but may be related to the higher surfactant concentration interfering with complete receding of the droplet into a globular form. Other factors critical in deposit formation are solvents, which are fre- 
quent constituents of commercial surfactant preparations and surfactant blends. Evaporation, which depends on the vapor pressure of the solvent, may cause a continuous shift in the composition of the solution of the drying droplet. Since most solvents are surface active, surface tension of the solution is likely to change during evaporation. Whereas the initially low surface tension would increase spreading of the droplet,. the higher surface tension after solvent evaporation may result in localized deposition as the droplet recedes. Additionally, viscosity of the solution in the droplet would be expected to increase as the solvent evaporates. Both events would favor annular deposition: Further, deposit formation would be affected by adsorption of the surfactant to the leaf surface, thereby altering the polarity of the surface. Thus, as the droplet advances during spreading, leaf surface polarity would differ from when it recedes during droplet drying. Although the precise mechanisms involved in deposit formation are not known, surface tension of the solution and polarity and fine-structure of the leaf surface are assumed to be critical factors. There was no clear relationship between shape of deposit and enhancement of uptake, although larger droplet/leaf and deposit/leaf interfaces appeared to be advantageous, but clearly other factors were involved.

Surfactants may also have direct effects on cuticular permeability that are not completely understood. The poor performance of Silwet L-77 was probably the result of surfactant degradation, for silicone-based surfactants are hydrolyzed in acidic solutions (Knoche et al., 1991), resulting in a marked increase in surface tension and higher contact angles.

When inhibition of flower initiation by various $\mathrm{GA}_{3} /$ surfactant combinations was evaluated in the field, Regulaid markedly increased biological response to $\mathrm{GA}_{3}$. Ortho X-77 was among the least effective surfactants, having no significant effect compared with the control $\left(\mathrm{GA}_{3}\right.$ only) (M. J. B., unpublished data). One would predict the opposite from the data for absorption over $24 \mathrm{~h}$ (Table 3). However, the long-term time-course of Regulaid and Ortho X-77 shows that Regulaid increased GA uptake linearly with time, while without surfactant or with Ortho $\mathrm{X}-77 ; \mathrm{GA}_{3}$ uptake leveled off within $12 \mathrm{~h}$ after treatment (Fig. $3)$.

Stomatal pore penetration does not appear to be a factor because the kinetics of uptake in the control (minus surfactant) and in the Ortho X-77 treatment were similar (Fig. 3). Stomatal infiltration is unlikely to occur from aqueous solutions having a surface tension of $70.8 \mathrm{mN} \cdot \mathrm{m}^{-1}$ (Schonherr and Bukovac, 1972). Deposits from droplets of solutions containing Regulaid and Ortho X-77 were similar (Fig. 2 E and F). However, the physical/chemical microenvironment of the a.i. in the deposit may be quite different. The decrease in the rate of $\mathrm{GA}_{3}$ penetration for control and Ortho X-77 treatments could be explained by a rate limiting resorption of $\mathrm{GA}_{3}$ from the dry deposit (e.g., due to limited mobility of the a.i. in the deposit matrix). Characteristics of the Regulaid deposit my allow for continuing penetration by maintaining a higher mobility of $\mathrm{GA}_{3}$ in the deposit matrix (e.g., by creating a gel-like residue). In this type of residue, one would expect the a.i. to be mobile, hence permitting continuous resorption and long-term penetration.

In the surfactant-concentration response study with Ortho X77 at concentrations $>0.0313 \%$, the high uptake after $96 \mathrm{~h}$ may have been related to surfactant-induced phytotoxicity. In these treatments, as with $0.25 \%$ Ortho X-77 tested $24 \mathrm{~h}$ after application, the leaf tissue showed discoloration in the droplet area upon air drying.

Uptake in the leaf disk system was consistently higher (about two times) than in the time-course study with entire leaves. Although the magnitude of the response was different, the qualitative relationships were similar and thus we believe that the leaf disk system provides a convenient and effective model system for uptake studies under controlled environments often not possible with intact systems.

In conclusion, surfactants affect the amount of the a.i. absorbed and the kinetics of uptake. To our knowledge, no conclusive information is available on the relationship between uptake kinetics and biological response. Detailed field experiments are needed to show whether the differences in surfactant-enhancement of $\mathrm{GA}_{3}$ absorption by sour cherry leaves observed in our studies translate into differences in biological response at the whole-plant level.

\section{Literature Cited}

Baker, E.A. 1974. The influence of environment on leaf wax development in Brassica oleracea var. gemmifera. New Phytol. 73:955-966.

Bukovac, M.J., J.A. Flore, and E.A. Baker. 1979. Peach leaf surfaces: Changes in nettability, retention, cuticular permeability, and epicuticular wax chemistry during expansion with special reference to spray application. J. Amer. Soc. Hort. Sci. 104:611-617.

Bukovac, M.J., J. Hull, Jr., C.D. Kesner, and R.P. Larsen. 1986a. Prevention of flowering and promotion of spur formation with gibberellin increases cropping efficiencv in 'Montmorency' sour cherry. Annu. Rpt. Mich. State Hort, Soc. 116:122-131.

Bukovac, M. J., D.L. Reichard, and R.E. Whitmoyer. 1986b. The spray application process: central for the efficient use of growth regulators in tree fruits. Acts Hort. 179:33-45.

Coggins, C.W. Jr., G.L. Henning, and M.F. Anthony. 1989. Possible methods to increase efficacy of gibberellic acid applied preharvest to navel orange trees. Second Intl. Symp. Adjuvants for Agrochem., Blacksburg, Va. (Abstr. 62.)

Fogg, G.E. 1947. Quantitative studies on the wetting of leaves by water. Proc. Royal Soc. London B, 134:503-522.

Greenberg, J., E.E. Goldschmidt, S. Schechter, S.P. Monselise, and D. Galili. 1984. Improving the uptake of gibberellic acid (GA,) by Citrus fruit and leaves. Proc. llth Annu. Meeting Plant Growth Regulat. Soc. Amer. p. 1625 .

Greenberg, J., S.P. Monselise, and E.E. Goldschmidt. 1987. Improvement of gibberellin efficiency in prolonging the citrus harvest season by the surfactant L-77. J. Amer. Soc. Hort. Sci. 112:625-629.

Holloway, P.J. 1969. The effects of superficial wax on leaf nettability. Annu. Applied Biol. 63:145-153.

Holloway, P.J. and D. Stock. 1990. Factors affecting the activation of foliar uptake of agrochemicals by surfactants, p. 303-337. In: D.R. Karsa (cd.). Industrial applications of surfactants II. Spec. Pub. no. 77. Royal Soc. Chem., Cambridge, U.K.

Knoche, M., H. Tamura, and M.J. Bukovac. 1991, Stability and performance of organosilicone surfactants: Effect of $\mathrm{pH}$, temperature and concentration on L-77. J. Agr. Food Chem. 39:202-206.

Knoche, M., N.K. Lownds, and M.J. Bukovac. 1989. Factors affecting the absorption of gibberellin $\mathrm{A}$; by sour cherry leaves. HortScierrce 24:113.

Leece, R.D. 1978. Foliar absorption in Prunus domestics L. I. Nature and development of the surface wax barrier. Austral. J. Plant Physiol. 5:749766.

Mack, G.L. 1936. The determination of contact angles from measurements of the dimensions of small bubbles and drops. J. Phys. Chem. 40:159-167.

Norris, R.F, and M.J. Bukovac. 1972. Influence of cuticular waxes on penetration of pear leaf cuticle by 1-naphthaleneacetic acid. Pesticide Sci. 3:705-708.

Parker, K. G., L.J. Edgerton, and K.D. Hickey. 1969. Gibberellin treatment for yellows-infected sour cherry trees. Farm Res. 29:8-9.

Schönherr, J. and M.J. Bukovac. 1972. Penetration of stomata by liquids: dependence on surface tension, nettability and stomata] morphology. Plant Physiol. 49:813-819.

Silcox, D. and P.J. Holloway. 1986. A simple method for the removal and assessment of foliar deposits of agrochemicals using cellulose acetate film stripping. Aspects of applied biology 11. Biochemical and physiological techniques in herbicide research. Assn. Applied Biol., Nottingham, Trent Polytechnic, U.K. p. 13-17.

Taylor, F. E., L.G. Davies, and A.H. Cobb. 1981. An analysis of the epicuticular wax of Chenopodium album leaves in relation to environmental change, leaf nettability and the penetration of the herbicide bentazone. Annu. Applied Biol. 98:471-478. 